\title{
Auditory Training and Adult Rehabilitation: A Critical Review of the Evidence
}

\author{
Kit Brouns, Amr El Refaie (Corresponding author) \& Helen Pryce \\ Centre for Hearing and Balance Studies, University of Bristol \\ Bristol, 8 Woodland Road, BS8 1TN, UK \\ Tel: 4411-7331-7747Ｅ-mail: A.ElRefaie@bristol.ac.uk
}

Received: October 8, 2010 Accepted: October 26, 2010 doi:10.5539/gjhs.v3n1p49

\begin{abstract}
Auditory Training (AT) describes a regimen of varied listening exercises designed to improve an individual's ability to perceive speech. The theory of AT is based on brain plasticity (the capacity of neurones in the central auditory system to alter their structure and function) in response to auditory stimulation. The practice of repeatedly listening to the speech sounds included in AT exercises is believed to drive the development of more efficient neuronal pathways, thereby improving auditory processing and speech discrimination. This critical review aims to assess whether auditory training can improve speech discrimination in adults with mild-moderate SNHL. The majority of patients attending Audiology services are adults with presbyacusis and it is therefore important to evaluate evidence of any treatment effect of AT in aural rehabilitation. Ideally this review would seek to appraise evidence of neurophysiological effects of AT so as to verify whether it does induce change in the CAS. However, due to the absence of such studies on this particular patient group, the outcome measure of speech discrimination, as a behavioural indicator of treatment effect is used instead. A review of available research was used to inform an argument for or against using AT in rehabilitative clinical practice. Six studies were identified and although the preliminary evidence indicates an improvement gained from a range of AT paradigms, the treatment effect size was modest and there remains a lack of large-sample RCTs. Future investigation into the efficacy of AT needs to employ neurophysiological studies using auditory evoked potentials in hearing-impaired adults in order to explore effects of AT on the CAS.
\end{abstract}

Keywords: Auditory training, Speech discrimination, Rehabilitation \& Hearing impaired adults

\section{Abbreviations:}

Auditory Training (AT)

Randomised controlled trials (RCTs)

Sensori-neural hearing loss (SNHL)

Central Auditory System (CAS)

\section{Introduction}

Auditory training (AT) is a term used to describe a prescribed regimen of listening exercises designed to improve an individual's ability to perceive speech sounds. Different views exist as to what AT should consist of (Sweetow and Palmer, 2005) but at the centre of all approaches is the aim to enhance a patient's communication skills. There is a growing body of evidence showing the benefits of using AT in the rehabilitation of cochlear implant patients (Stacey and Summerfield, 2007; Fu et al, 2005) and patients with central auditory processing disorder (CAPD) (Musiek 2005, 2006; Chermak et al, 2002). Although these patient groups are important candidates for AT, the focus of this review is on adults with mild-moderate sensorineural hearing loss (SNHL).

Deterioration in hearing with advancing age (e.g. presbyacusis) is one of the most prevalent conditions affecting the adult population (Dalton et al, 2003). With life expectancy increasing, the number of people with hearing impairment will continue to grow (Cohen et al, 2004; Betlejewski, 2006). The typical pattern of high frequency hearing loss with presbyacusis results in a reduced ability to perceive speech particularly in background noise (Burk and Humes, 2008; Crandell, 1998). Current models of aural rehabilitation for this patient group often seek to remedy speech perception difficulties by fitting hearing aids to increase the signal to noise ratio but there is evidence to suggest that this in itself is not enough (Wright, 2007; Kricos, 2006). Findings of poor patient 
satisfaction with hearing aids alone suggests that there needs to be a concentrated effort to examine other avenues and even re-visit past practices such as AT (Pichora-Fuller and Singh, 2006; Sweetow, 2005).

Auditory training was once a popular element of aural rehabilitation for adults with hearing impairment (Musiek, 2006) but it's use and popularity has declined over recent years due to the time-cost implications and a lack of robust evidence on efficacy (Sweetow, 2005; Bloom, 2004). Research into AT's application for patients with CAPD and cochlear implants, along with recent advances in neurophysiological tools for measuring changes in sensory processing pathways has led to an increased interest in how and for whom this intervention is of benefit (Ahissar, 2001; Neuman, 2005).

\subsection{Types of $A T$}

The terms "analytic" and "synthetic" are used in the literature to describe two broad approaches to Analytic focuses on improving consonant/syllable recognition via listening drills and synthetic refers to a range of exercises designed to improve sentence perception and tends to include some form of communication strategy teaching (Rubinstein and Boothroyd, 1987). Some authors also use terms such as "listening training" (Tremblay et al, 1997) or "perceptual training" (Stecker et al, 2006; Woods \& Yund, 2007) to describe a process of AT. Regardless of the terminology used, the listening tasks generally include lists of sentences, words or speech syllables presented in noise (background babble). These exercises are then repeatedly listened to by patients either at home via a computer-based programme or in clinic using live voice, tape recorded or computer-based presentation. Despite the variety of AT paradigms described in the literature they are all designed with the same objective of improving communication ability.

\subsection{Theory of $A T$}

The physiological theory underpinning AT is based on the capacity of the auditory cortex to reorganise itself in response to sensory experience (Bamiou and Luxon, 2008). Plasticity in the brain enables neuronal pathways to develop in direct response to environmental stimuli and although greater degrees of plasticity are apparent in early life, this capacity for change is retained into adulthood (Tremblay et al, 1997; Russo et al, 2004). Just as the CAS exhibits plasticity in response to stimulation, neuronal pathways also reorganise when there is deprived auditory input e.g. with hearing loss (Kral, 2007). In typical presbyacusis, the high frequency response is gradually reduced due to 'wear and tear' of the outer hair cells in the cochlea (Syka, 2002). These peripheral changes lead to altered neuronal organisation in the auditory cortex due to diminished levels of input (Stecker et al, 2006). Sensory deprivation research has found disruption of neurone maturation, limited dendrite branching and reduction of auditory nerve fibres (Moore and Linthicum, 2007). Functional imaging studies by Dietrich et al (2001) and McDermott et al (1998) have also revealed different frequency maps in the auditory cortex of subjects with SNHL and normal-hearing individuals, indicating cortical change in response to reduced auditory input (Recanzone et al, 1993).

Evidence of sensory deprivation with hearing loss needs to be addressed in models of patient rehabilitation. Whilst amplification can partially compensate for cochlear deficits by increasing sensory input, the actual process of repairing auditory processing pathways to aid speech perception is thought to require a different level of stimulation (Stecker et al, 2006; Neuman, 2005). The repeated and varied listening tasks of AT are argued to provide the stimulation required to promote 're-normalisation' of a deprived CAS and therefore should be used to rehabilitate these patients (Tremblay et al, 1997; Stecker et al, 2006; Sweetow and Henderson-Sabes, 2004).

\subsection{Support for theory}

Support for the plasticity theory of AT can be found in neurophysiological studies that have used auditory evoked potentials (AEPs) to demonstrate training-induced change in the auditory cortex (Tremblay et al, 1997; Tremblay and Kraus, 2002; Russo et al, 2004). Measurements of the N1-P2 complex and mis-match negativity $(\mathrm{MMN})$ cortical evoked potentials have been used to show that AT can alter the neural encoding of sound in normal-hearing individuals. The MMN is thought to reflect processes involved in stimulus discrimination whilst the N1-P2 complex reflects pre-attentive stimulus encoding and are therefore useful tools for examining processing in the auditory cortex (Neuman, 2005). Studies by Tremblay et al (1997) and Tremblay and Kraus (2002) have revealed increases in AEP amplitude after a period of AT suggesting improved neural synchrony in the auditory processing pathway. Improved speech discrimination measures obtained in the same participants are believed to represent the behavioural effect of training-induced change in the CAS. Although this evidence provides support to the basic premise of AT, these studies only used small numbers of normal-hearing individuals which limits generalisation of findings to the hearing impaired population. 


\section{Objectives}

The primary research question addressed here is: Does auditory training improve speech discrimination in hearing-impaired adults? Rationale for the clinical question posed by this review stems from the need to examine whether AT should be implemented by Audiology services.

\section{Methods}

\subsection{Inclusion criteria for studies}

This review considered the following research methodologies for inclusion: systematic reviews, randomised controlled trials (RCTs), and non-randomised observational case-control studies. Studies that examined the outcome effects on adult participants with hearing impairment (mild-moderate SNHL) were included with older adults (over 50 years old) being the main focus. Studies considered were those that assessed auditory training (or "perceptual training" and "listening training") either with or without comparison to a control group. A range of auditory training formats were included: syllable tasks, nonsense word lists, sentences, exercises in noise and in quiet, verbal exercises in clinic, generic computer-based software training packages for home or in-clinic use and listening exercises combined with communication strategy training.

\subsection{Outcome measures}

The outcome measures of primary interest included patient performance after AT on tasks that assessed: speech discrimination, speech perception, speech comprehension or syllable identification. Secondary outcome measures included any assessment of improved speech discrimination performance at patient follow-up as an indicator of the permanence of any treatment effect. Outcome measures of subjective improvement were also considered.

\subsection{Search strategy}

A multifield search strategy ("search 1") was used to specify the intervention of interest and the patient groups to be excluded from the search. A broader keyword search ("search 2") was also used to identify evidence that evaluated AT but had not specified it in the study title (see table 1). The following databases were searched: AMED (Allied and Complementary Medicine), EMBASE (biomedical database) and MEDLINE-1950 to present (National Library of Medicine's bibliographic database).

\subsection{Inclusion/Exclusion criteria}

The 52 papers identified from the search were examined for relevance to the clinical question using a set of inclusion and exclusion criteria. Studies that met the following inclusion criteria were selected for appraisal: 1) AT used as intervention, 2) participants were adults with mild-moderate SNHL (male or female), 3) participants were new, experienced or non-hearing aid users, 4) outcome measures of speech discrimination were employed and 5) study design was analytic rather than descriptive.

Papers were excluded from the review if the intervention, patient group or outcome measures were not relevant to the clinical question (table 2). One paper by Martin (2008) investigated a commercial AT software package called LACE: Listening and Auditory Communication Enhancement (Sweetow and Henderson-Sabes, 2004). Despite being the largest study $(n=625)$ it was excluded due to non-relevant outcome. Martin (2008) used an ambiguous measure of 'rate of hearing aid return' in a private clinic setting as an indicator of AT benefit without evaluation of speech discrimination or consideration of confounding factors.

The inclusion and exclusion criteria yielded 6 studies for further appraisal. An overview of this process can be found in figure 1

\subsection{Assessment of study quality}

Selected studies were assessed for strength of evidence and appropriateness to the clinical question. The internal and external validity of each study was appraised using the following criteria:

Methodology (weighting given to more robust experimental design)

Quality of randomisation (if used)

Inclusion of blinding (participants and/or experimenters)

Presence or absence of a control group for comparison of intervention effect

Size of study - number of participants (more value given to larger studies)

Selection procedure of participants - risk of bias? 
Relevance of participants to the focus population - typical patient group or potential bias?

Consideration of confounding variables

Quality and relevance of outcome measures

Examination of long-term outcomes from auditory training

Suitable data analysis

Were the study objectives met?

\section{Results}

\subsection{Research methods}

The selected studies included 1 systematic review, 2 randomised-controlled trials, and 3 non-randomised observational case-control trials comparing patients before and after-treatment. A summary of the intervention, patient group, outcome measure, key findings and main criticisms of the 6 studies are outlined in table 3 .

Participants used in all studies were adults with symmetrical bilateral SNHL. All studies included 'older listeners' of an average age range of 50-80 years apart from Bode and Oyer (1970) who used a younger demographic with ages from 21-60 years (median of 44 years old). The degree of SNHL was mild-moderate as determined by pure tone audiometry threshold and all participants had sloping high frequency SNHL typical of presbyacusis.

The auditory training paradigms used in the studies varied in terms of the stimuli used and the way in which it was presented. Two studies compared analytic and synthetic approaches (Kricos and Holmes, 1996; Rubinstein and Boothroyd, 1987) whilst the others investigated a version of analytic training or a combination of the two. The training stimuli used in the studies were presented to participants either via a computer-based package at home or in clinic ( 2 studies used this format), tape-recorded materials presented in a laboratory setting (2 studies), or live voice presentation of training material (1 study). All were presented in background noise.

A range of outcome measures were used in the 6 studies. All used some form of speech recognition measure in noise (syllable or sentence) but some used open and closed-set response formats whilst others used commercially available measuring tools such as the CUNY NDT test (City University of New York Nonsense Syllable Test) (Rubinstein \& Boothroyd, 1987). Despite the difference in methods, all studies aimed to use the measures to expose change in baseline performance between pre and post-training scores. Any significant change from baseline was hypothesised to represent a treatment effect.

\subsection{Reported results for primary and secondary outcomes}

A range of outcomes were reported in the selected studies. With regards to the primary outcome of improved speech discrimination, all studies reported a degree of improvement in measures recorded post-training, although the effect size and AT format varied. Secondary outcomes of interest to the review included findings of long-term retention of treatment effect. Burk and Humes (2008) measured retention of improved speech recognition up to 14 weeks after a 12 -week training programme and found slight decline but no significant change in performance. This study used a brief "refresher" to demonstrate that a short period of AT enabled participants to reach their maximum score and therefore suggests not only a retention of effect but also a faster capacity to return to peak performance. Rubinstein and Boothroyd (1987) also found retention of AT effect at one month follow-up and Stecker et al (2008) showed improved syllable identification was maintained 8 weeks after training ceased.

The Kricos and Holmes (1996) study was the only one to measure any subjective improvement from AT. They found that a 4 week programme (individual 1 hour session twice a week) resulted in improved scores on the Communication Profile for the Hearing Impaired (CPHI). The CPHI questionnaire is designed to assess psychosocial status of a patient and can be a useful indicator of how a patient perceives and copes with their hearing loss in daily life. No significant change was reported on the Hearing Handicap Inventory for the Elderly (HHIE) measure.

\subsection{Systematic review findings}

The systematic review by Sweetow and Palmer (2005) appraised 6 studies (dating from 1970 to 1996) for evidence of improved communication skills in hearing impaired adults and concluded that findings indicate efficacy of AT as an intervention but no single AT format could be highlighted as the best. Three of the studies appraised were RCTs and three were before/after effect trials with no controls. Three of the studies used were 
also selected by the present review for more detailed analysis: Bode and Oyer (1970), Rubinstein and Boothroyd (1987) and Kricos and Holmes (1996).

Systematic reviews can provide the highest level of evidence but still need assessing for quality to determine whether the results of the review are valid. Sweetow and Palmer (2005) used clear and relevant objectives in which to critically evaluate the evidence-base to support their clinical question. Inclusion and exclusion criteria were fully described and enabled the identification and synthesis of appropriate studies to draw conclusions of AT efficacy. Two RCTs reviewed by Sweetow and Palmer used audio-visual interventions which although were excluded from the current review, can still be used to demonstrate overall effects of AT.

A major weakness of this paper is in the limited appraisal made on the validity of statistical analysis used by the included studies. The description and comment made by the author's on this aspect is restricted to whether studies included a power calculation. Although a power calculation is important when determining the appropriateness of a sample size, more information is needed if an accurate judgement can be made on the quality of data analysis. Despite this limitation, the quality of other aspects of this paper means that confidence can be placed in the review's findings of AT efficacy.

\subsection{Randomised controlled trial findings}

The RCT by Stecker et al (2006) used two experiments to evaluate an 8 week PC based syllable AT paradigm in a group of new hearing aid users $(n=23)$ and a group of experienced hearing aid users $(n=8)$. Participants in both experimental groups were randomly assigned to either an immediate training (IT) or a delayed training (DT) group. The DT group acted as the control. Results from syllable identification in noise tests showed a significant improvement in performance in both experimental groups which was retained at 8 week follow-up.

In the IT new hearing aid user group speech discrimination improved by $10.6 \%$ from baseline which was statistically significantly greater than the $6 \%$ improvement found from hearing aid fitting alone (DT control group). The DT group also showed improved performance once training commenced, indicating that significant change in baseline score was achieved even when training was completed 8 weeks after hearing aid fitting. Improved performance was found to generalise to measures using untrained (e.g. new voices) but no measures of running speech were used. Greater accuracy was found for difficult phonemes ( $\mathrm{f} /$ th $/$ ) after AT in all experimental groups.

Kricos and Holmes (1996) used a 4 week programme (1 hour session, twice a week) to compare a purely analytic approach (structured syllable drills) to an active listening paradigm in a sample of 78 adults with SNHL. Although the author's do not use the term 'synthetic', the active listening paradigm they illustrate can be suitably described as this, with a combination of listening drills ("speech tracking") and communication strategy training. Three outcome measures were used to assess change in speech discrimination and subjective quality of life. The Connected Speech Test (CST) scores showed easier speech recognition in noise after training $(p<0.05)$ for the active listening group but not for the analytic intervention. The CPHI questionnaire showed significant improvement in several subscales, but of note no significant change was detected by the HHIE.

The major strength of these studies is that they are RCTs with Kricos and Holmes (1996) using a 'no-training' control group $(\mathrm{n}=26)$ and Stecker et al (2006) a 'delayed training' group. Any significant change in baseline performance after training can therefore more confidently be attributed to the effect of AT rather than confounding factors. The randomisation of participants reduces bias, increasing the likelihood that findings are a true reflection of the effects of the intervention. The actual description of how participants were randomised was poor. Kricos and Holmes explain that random allocation was done on a 'rotating basis' without further explanation whilst Stecker et al offer no procedural detail. This makes it difficult to evaluate the quality of study methodology. Another weakness is the lack of blinding, making it difficult to confidently eliminate any experimenter or participant bias involved in allocation of participants to the treatment and control groups. A further problem with the study by Stecker et al (2006) is that it only had male participants. This may cause concern about applying the findings to a mixed-sex patient group, but no significant sex-differences have been identified in the other mixed-sex studies.

In addition to the use of control groups and randomisation, strengths of the two RCT studies can be found in the thorough and appropriate analysis of data they describe. Both studies used analysis of variance tests to determine the statistical significance of changes in outcome measures and to reveal any interaction effects on results. Kricos and Holmes (1996) checked for the effect of confounding variables such as stroke, dementia and sight whilst Stecker et al (2006) analysed correlations between factors such as age, number of hours training and type of hearing aid. The use of statistical tests to examine the impact of confounding variables increases confidence in findings being a true representation of actual intervention effect. The large sample size used by Kricos and 
Holmes $(n=78)$ also increases the statistical power of the data sets used in the study. If a larger number of subjects demonstrate a statistically significant change in performance after AT, then this provides a better representation of potential intervention effect on the wider population.

\subsection{Non-randomised case-control study findings}

The 3 case-control trials reviewed here found evidence of AT efficacy with improved speech discrimination after training. Bode and Oyer (1970) examined the effect of 4 variations of AT paradigm (speech in noise varied or constant and open or closed-set response format) in 32 adults with mild SNHL over a 1 day training programme with no follow-up. Three speech recognition tests were used to examine treatment effect: (1) W-22 test where the participant is required to repeat verbally the word they heard in background noise (2) Rhyme test which required a written response from lists of word stems (e.g. _ot, _ ay) and (3) Semi-diagnostic test where patients circle the correct response from a closed set word list. T-tests comparing the results before and after training showed a significant improvement in speech recognition performance of $7.7 \%$ on the W-22 (p<0.01) and 3.5\% on the Rhyme $(<0.05)$ but none on the semi-diagnostic test.

A small but significant effect on speech recognition was also found in the non-randomised study of Rubinstein and Boothroyd (1987) that compared the efficacy of synthetic versus a combined analytic and synthetic approach in 20 adults with SNHL. The synthetic-only paradigm consisted of listening practice and discussion whilst the combined intervention also included consonant drills. The training programme consisted of $8 \mathrm{x} 1$ hour sessions over 4 weeks and a measure of long-term benefit was obtained 4 weeks post-training. Three tests of speech recognition were used: CUNY nonsense syllable test, revised speech perception in noise (RSPIN) low predictability items and RSPIN high predictability items. The study used a 4 week run-in period as a control prior to starting the intervention. Results showed improved performance when compared to scores obtained after the control period $(\mathrm{p}<0.01)$ which was retained at the 1 month follow-up. No significant difference was found between the two AT approaches or outcome test used.

Support for efficacy of an analytic approach to AT was also found by Burk and Humes (2008) who found improved open and closed-set word recognition performance in noise after 12 weeks (20-24 hours) of PC-based training on word and sentence stimuli. Stimuli consisted of lexically easy (high in daily occurrence) and lexically hard (low frequency) words and open and closed word-set recognition tests were used to assess change in performance Participants were measured at baseline, then again at a mid-way point after 9-11 sessions of hard word training and then again after the final 9-11 sessions of easy word training. Retention of benefit was assessed at 14 weeks post-training. Training on hard words showed a significant $47.4 \%(p<0.001)$ improvement with the open-set response test and $16.4 \%(p<0.001)$ in the closed-set condition. Baseline scores for the easier closed-set response format (where multiple choice options are given) were higher than the open-set which can explain the difference in degree of improvement. The sessions on easy word training yielded similar results with $40.4 \%$ (open-set) and $17.2 \%$ (closed-set). This improved performance was found to generalise to recognition with words spoken by an unfamiliar talker but not to untrained words spoken in running speech.

Two of the studies assigned participants to treatment groups based on a system of matching patient variables to create similar and therefore comparable subject groups. Variables used by Bode and Oyer (1970) and Rubinstein and Boothroyd (1987) included patient age, intelligence, duration of hearing loss, average pure-tone thresholds and duration of hearing aid use. Although this controlled matching of cases is not as strong at eliminating bias as a blinded RCT design, this process does limit within and between group variability and therefore reduces the effect of confounding factors on results.

A fundamental weakness of these studies is the lack of a control group. It is difficult to confidently attribute change in baseline performance to the intervention of AT without the use of some form of no-treatment control group. The only study which attempted to provide a suitable comparison group was that of Rubinstein and Boothroyd (1987) who took performance measures after a period of no-training so that subjects could then act as their own control. Although not ideal, this 'pseudo-control' method is better than having no group to compare to the experimental condition.

The quality of data analysis varied between these three studies. Both the Bode and Oyer (1970) and Burk and Humes (2008) studies used t-tests to calculate significant differences between the pre and post-training scores. Bode and Oyer described the statistical analysis in detail and used a larger sample size to obtain significant results whereas Burk and Humes only provide a sparse description of data handling and used a small sample of 8 subjects. Bode and Oyer (1970) and Rubinstein and Boothroyd (1987) performed analysis of variance tests to monitor whether exposure to different combinations of listening condition, training material or outcome test influenced results. This statistical analysis enabled the authors to draw stronger conclusions about treatment 
effects detected due to elimination of potential confounding factors. The lack of analysis of variance used in the study by Burk and Humes, along with the small study sample reduces confidence in whether the significant improvement observed can be reliably attributed to the intervention effect of AT. A concern with the data analysis in Rubinstein and Boothroyd's study is that one participant dropped out of the study before the final session and rather than removing this data set from analysis, the authors opted to use 'dummy' data based on previous performance for statistical appraisal.

The length of training programme used ranged from a 1 day intensive training (Bode and Oyer) to 12 weeks (Burk and Humes). Although this review considered all formats of AT, the short programme used by Bode and Oyer ( 5 x 25 minute sessions in one day) limits the applicability of this evidence to clinical practice. The authors explain that the original aim was to assess AT over a 6-10 week period but due to lack of enthusiasm from participants it was changed to 1 day. They were therefore also not able to look at long term outcomes.

A frequent concern with trials relates to recruitment and maintenance of motivation of study participants. In these studies where the intervention requires a high level of active participation, more motivated participants may achieve more than the potentially less motivated clinic patient. One study (Burk and Humes, 2008) however added to this bias by paying participants not only to attend but also providing a performance bonus.

\section{Discussion}

This critical appraisal has shown methodological weaknesses in study design and execution to some extent in all studies included in this review. Conclusions drawn from the uncontrolled trials have to be made with caution, in particular the study by Burk and Humes (2008). The relevance of the findings from Bode and Oyer (1970) is questionable given their intervention and lack of long term outcomes. Focusing therefore on the controlled trials, the Rubinstein and Boothroyd study and the two RCTs did show statistically significant improvements. This was however limited to specific AT techniques and outcome measures. The statistical significance of the results does not necessarily mean they are clinically significant. For example, two subjective measures of hearing disability were used by Kricos and Holmes but only one showed a positive result. This brings into question whether there is indeed a clinical improvement to a patient's quality of life.

The evidence-base is encouraging but in its infancy with more required before AT can be recommended as part of aural rehabilitation for adults with presbyacusis. Future studies need to establish clinically relevant outcome measures potentially combined with physiological measurements to assess the benefits of AT. Ideally trials should also assess the different types of AT and identify which patients are likely to benefit most. Finally a cost effectiveness study would need to demonstrate benefit prior to routine clinical use.

\subsection{Greater consensus in research approach needed}

Kricos and Holmes (1996) propose that the modest effect sizes found in research may be because of ineffective or insensitive outcome measures and argue the importance of working towards a more unified approach to AT research. The heterogeneity found in the current evidence-base (different AT materials, sample size, outcome measures) makes it difficult to draw direct comparisons between studies and makes little progress in determining which AT paradigm is most effective (Sweetow and Palmer, 2005). A consensus needs to be reached on which outcome measures should be used to detect change in speech discrimination, so that future investigation into AT formats can directly compare findings between studies. With a more unified approach, the existing gaps in evidence can be filled with investigation into the optimum number and type of words to use, length of training program, number of talkers and mode of presentation (Burk et al, 2006; Sweetow, 2005; Wright, 2007).

The importance of developing and using clinically relevant outcome measures in future research is highlighted by the findings of Burk and Humes (2008). Improved speech perception was found on tests that assessed word and sentence recognition but not on the more realistic tests of running speech. This type of test could represent a more clinically significant measure and until research adopts a set of more realistic 'conversation' measures, the evidence-base will fall short in convincing sceptics of AT benefit.

\subsection{Neurophysiological studies}

Due to a lack of neurophysiological studies on this particular patient group, evidence of underlying plasticity and the influence of AT can only be extrapolated from studies on normal-hearing individuals (Russo et al, 2005; Tremblay et al, 1997). It is therefore difficult to interpret the genuine effect of AT because it is not yet fully understood how the behavioural measures of improved speech perception come about. Is it actual reorganisation of the neuronal pathways in the CAS or are the positive findings reflecting a therapeutic effect or some learning process? (Stacey and Summerfield, 2007). The evidence required to answer this question can only be obtained 
from research that combines neurophysiological and behavioural measures to study the brain-behavioural relationship of AT in this patient group (Tremblay and Kraus, 2002).

Advances in ability to measure activity in the auditory system in response to sound stimulation (via auditory evoked potentials and functional brain imaging techniques) means that the future of research should adopt these methods to reflect the physiological effect that AT has on the CAS of hearing impaired individuals (Neuman, 2005). It seems strange that at the core of AT is the theory of how is can drive CAS plasticity, yet research so far has not used the methods required to evaluate this theory in the relevant patient group (English et al, 2003).

\subsection{Further examination on patient characteristics}

There are findings to suggest that patient factors can influence the degree of AT gain observed and presents the need for more detailed examination (Sweetow and Palmer, 2005). Stecker et al (2006) found that the performance of older participants on a nonsense syllable test was significantly poorer than younger participants but that the degree of improvement from pre to post-training was generally greater in the older group (although not statistically significant). These findings raise questions about the possible impact of patient age (and other factors) on amount of AT benefit and therefore needs addressing in future.

\subsection{Implementation issues}

Unfortunately there is not enough evidence to reach a consensus on how to apply this intervention which limits the application of this evidence to clinical practice. Without robust evidence advocating the use of one AT approach over another, problems will be encountered when implementing change to Audiology services that are already pushed for resources (Bloom, 2004). No conclusive evidence exists on which individual AT paradigm is most effective for this patient group (Sweetow and Palmer, 2005). There is, however, a trend suggesting that greater benefit can be found when AT programmes combine the analytic listening drills with the more general communication skills training offered by the synthetic approach (Rubinstein and Boothroyd, 1987; Kricos and Holmes, 1996). Using AT to encourage the development of wider communication skills in conjunction with the fitting of hearing aids could therefore offer the most comprehensive and effective approach to rehabilitation (Sweetow, 2005; Wright, 2007).

The importance of using a treatment approach that goes beyond the fitting of amplification is not a new idea, with today's literature on aural rehabilitation promoting the importance of including counselling, communication strategies, psychosocial impact assessment and involvement of significant others for more successful outcomes (Hogan, 2001; Tye-Murray, 2004; Alpiner and McCarthy, 2000). Despite the lack of consensus on what AT programme to implement, evidence of greater benefits of AT over the fitting of amplification on its own and the findings of long-term benefits can be used to support the introduction of AT exercises as part of a broader approach to rehabilitation (Burk and Humes, 2008; Rubinstein and Boothroyd, 1987; Stecker et al, 2008).

\subsection{Future Directions}

The development of computer-based packages has brought rise to the prospect of delivering AT via a self-paced programme suitable for home-use (Burk and Humes, 2008; Bloom, 2004). These training packages could potentially overcome the time-cost barrier to implementing AT clinical rehabilitation practice. Several soft-ware packages have been developed for commercial use in the United States such as the McAid and LACE (Sweetow and Henderson-Sabes, 2004). Although these packages have not been specifically reviewed here they may prove useful in stimulating the design of a free AT programme for home or clinic use. Although potentially valuable for the overall promotion of AT, these computer packages wont be suitable for all patients and will depend on patient capability (sight, dexterity) and motivation (Bloom, 2004). Developments in methods of access to Auditory Training materials have been made ahead of evidence establishing their effectiveness

\section{Conclusion}

This review has found promising signs within the evidence-base supporting the use of auditory training in the rehabilitation of adults with presbyacusis. There are however methodological weaknesses and a lack of statistically significant clinically relevant outcomes. The evidence-base is limited to small uncontrolled studies and two RCTs. They reported some statistically significant improvements in outcome but these were modest. Rather than being able to change practice the current evidence-base should be used as a platform to stimulate the future direction of AT investigation through recognition of past methodological flaws and gaps in research. There is potential for including newer techniques both within AT (e.g. computer-based packages) and in assessing its effect through neurophysiological measurements. At present one cannot conclusively say that auditory training improves speech discrimination in hearing impaired adults. 


\section{References}

Ahissar, M. (2001). Perceptual training: A tool for both modifying the brain and exploring it. Proceedings of the National Academy of Sciences of the United States of America, 98(21), pp. 11842-11843.

Alpiner, J. G. and McCarthy, P. A. (2000). Rehabilitative Audiology: Children \& Adults ( $3^{\text {rd }}$ edition). Maryland: Lippincott Williams \& Wilkins.

Barcroft, J., Sommers, M. and Tye-Murray, N. (2007). What learning a second language might teach us about auditory training. Seminars in Hearing, 28(2), pp. 151-162.

Bamiou, D. and Luxon, L. M. (2008). Auditory processing disorders: Can cause educational, behavioural, and social problems but are often undiagnosed. BMJ, 337, pp.1306-1307.

Betlejewski, S. (2006). Age connected hearing disorders (presbyacusis) as a social problem. Otolaryngol Pol, 60(6), pp. 883-886.

Bloom, S. (2004). Technologic advances raise prospects for a resurgence in use of auditory training. The Hearing Journal, 57(8), pp. 19-23.

Bode, D. L. and Oyer, J. J. (1970). Auditory training and speech discrimination. Journal of Speech and Hearing Research, 13, pp. 839-855.

Bloom, J. L. (1980). The development of independent auditory training activities for severely and profoundly deaf students using audiovisual equipment. American Annals of the Deaf, 125(6), pp. 695-701.

Bloom, S. (2004). Technologic advances raise prospects for a resurgence in use of auditory training. Hearing Journal, 57(8), pp. 19-24.

Burk, M. H. and Humes, L. E. (2008). Effects of long-term training on aided speech-recognition performance in noise in older adults. Journal of Speech, Language, and Hearing Research, 51(3), pp. 759-771.

Burk, M., Humes, L., Amos, N. and Strauser, L. (2006). Effect of training on word-recognition performance in noise for young normal-hearing and older hearing-impaired listeners. Ear and Hearing, 27, pp. 263-278.

Chermak, G. D. and Musiek, F. E. (2002). Auditory training: Principles and approaches for remediating and managing auditory processing disorders. Seminars in Hearing, 23(4), pp. 297-308.

Cohen, S. M., Labadie, R. F., Dietrich, M. S. and Haynes, D. S. (2004). Quality of life in hearing-impaired adults: the role of cochlear implants and hearing aids. Otolaryngol Head Neck Surgery, 131, pp. 413-422.

Conrod, B. E. and Overbury, O. (1998). The effectiveness of perceptual training and psychosocial counselling in adjustment to the loss of vision. Journal of Visual Impairment and Blindness, 92(7), pp. 464-482.

Crandell, C. C. (1998). Hearing aids: Their effects on functional health status. The Hearing Journal, 51, pp. 22-30.

Dalton, D. S., Cruickshanks, K. J., Klein, B. E. K., Klein, R., Wiley, T. J. and Nondahl, D. M. (2003). The impact of hearing loss on quality of life in older adults. The Gerontologist, 43(5), pp. 661-668.

Dietrich, V., Nieschalk, K., Stoll, W., Rajan, R. and Pantev, C. (2001). Cortical reorganisation in patients with high frequency cochlear hearing loss. Hearing Research, 158(1-2), pp. 95-101.

Eadie, T. L. and Baylor, C. R. (2006). The effect of perceptual training on inexperienced listeners' judgments of dysphonic voice. Journal of voice, 20(4), pp. 527-544.

Eberts, R. and Schneider, W. (1986). Effects of perceptual training of sequenced line movements. Perception \& Psychophysics, 39(4), pp. 236-247.

English, K., Martonik, J. and Moir, L. (2003). An auditory training technique to improve dichotic listening. The Hearing Journal, 56 (1), pp. 34-38.

Ethier, M., Baribeau, J. M. C. and Braun, C. M. J. (1989). Computer-dispensed cognitive-perceptual training of closed head injury patients after spontaneous recovery. Study 1: Speeded tasks. Canadian Journal of Rehabilitation, 2(4), pp. 223-233.

Ethier, M., Baribeau, J. M. C. and Braun, C. M. J. (1989). Computer-dispensed cognitive-perceptual training of closed head injury patients after spontaneous recovery. Study 2: Non-speeded tasks. Canadian Journal of Rehabilitation, 3(1), pp. 7-16.

Fu, Q., Galvin, J., Wang, X. and Nogaki, G. (2005). Moderate auditory training can improve speech performance of adult cochlear implant patients. Acoustical Research Letter online, 6(3), pp 106-111. 
Fu, Q. J., Galvin, J., Wang. X. and Nogaki, G. (2004). Effects of auditory training on adult cochlear implant patients: A preliminary report. Cochlear Implants International, 5(Suppl 1), pp. 84-90.

Grimault, N., Micheyl, C., Carlyon, R. P. and Collet, L. (2002). Evidence for a two pitch encoding mechanisms using a selective auditory training paradigm. Perception \& Psychophysics, 64(2), pp. 189-197.

Hogan, A. (2001). Hearing Rehabilitation for Deafened Adults: A Psychosocial Approach. London: Whurr Publishers.

Iverson, P., Hazan, V. and Bannister, K. (2005). Phonetic training with acoustic cue manipulations: A comparison of methods for teaching English /r/-/1/ to Japanese adults. Journal of the Acoustical Society of America, 118(5), pp. 3267-3278.

Jackson, R. C. and Farrow, D. (2005). Implicit perceptual training: How, when, and why? Human Movement Science, 24(3), pp. 308-325.

Jagacinski, R. J., Grrenburg, N., Liao, M. J. and Wang, J. (1993). Manual performance of a repeated pattern by older and younger adults with supplementary auditory cues. Psychology \& Aging, 8(3), pp. 429-439.

Jerger, J. (2006). Auditory training. [Comment]. Journal of the American Academy of Audiology, 17(8), pp. 536-537.

Jerger, J. (2006). Auditory training. Journal of the American Academy of Audiology, [editorial] 17(8).

Kelly, A. S., Purdy, S. C. and Thorne, P. R. (2005). Electrophysiological and speech perception measures of auditory processing in experienced adult cochlear implant users. Clinical Neurophysiology, 116(6), pp. $1235-1246$.

Kral, A. (2007). Unimodal and cross-modal plasticity in the 'deaf' auditory cortex. International Journal of Audiology, 46, pp. 479-493.

Kricos, P. B. (2006). Audiologic Management of older adults with hearing loss and compromised cognitive/psychoacoustic auditory processing capabilities. Trends in Amplification, 10(1), pp. 1-21.

Kricos, P. B. and Holmes, A. E. (1996). Efficacy of audiologic rehabilitation for older adults. Journal of the American Academy of Audiology, 7(4), pp. 219-229.

Lakshminarayanan, K. and Tallal, P. (2007). Generalisation of non-linguistic auditory perceptual training to syllable discrimination. Restorative Neurology and Neuroscience, 25(3-4), pp. 263-272.

Lundborg, T. (1980). Clinical experiences with communication instruments in adults with sensorineural hearing loss. Audiology, 19(3), pp. 189-201.

Lynch, W. (1989). Computer-assisted visual-perceptual training. Journal of Hearing Trauma and Rehabilitation, 4(2), pp. 75-77.

Mann, L. (1970). Perceptual training: misdirections and redirections. American Journal of Orthospsychiatry, 40(1), pp. 30-38.

Mapes, F. M. and Moreau, R. M. (1980). The use of decoy sentences to measure auditory training gains. American Annals of the Deaf, 125(3), pp. 394-399.

Martin, D. P. and Wolfe, V. I. (1996). Effects of perceptual training based upon synthesized voice signals. Perceptual and Motor Skills, 83, pp. 1291-1298.

Martin, M. (2007). Software-based auditory training program found to reduce hearing aid return rate. The Hearing Journal, 60(8), pp. 32-35.

Matkin, N. D. and Olsen, W. O. (1973). An investigation of radio frequency auditory training units. American Annals of the Deaf, 118(1), pp. 25-30.

McDermott, H. J., Lech, M., Kornblum, M. S. and Irvine, D. R. (1998). Loudness perception and frequency discrimination in subjects with steeply sloping hearing loss: Possible correlates of neural plasticity. J Acoust Soc of America, 104(4), pp. 2314-2325.

Moore, J. K. and Linthicum, F. H. (2007). The human auditory system: A timeline of development. International Journal of Audiology, 46, pp. 460-478.

Moreau, R. M. (1980). Factors affecting auditory training gains. American Annals of the Deaf, 125(3), pp. 439-41.

Musiek, F. E. (2006). Auditory training and CAPD: A short history. The Hearing Journal, 59(8), pp. 52. 
Musiek, F. E. (2005). Temporal (auditory) training for (C)APD. The Hearing Journal, 58(2), pp. 46.

Musiek, F. E. and Schochat, E. (1998). Auditory training and central auditory processing disorders. A case study. Seminars in Hearing, 19(4), pp. 357-366.

Musiek, F. E., Shinn, J. and Hare, C. (2002). Plasticity, auditory training, and auditory processing disorders. Seminars in Hearing, 23(4), pp. 263-275.

Neuman, A. C. (2005). Central auditory system plasticity and aural rehabilitation in adults. Journal of Rehabilitation Research and Development, 42(Suppl2), pp. 169-185.

Niday, K. J. and Elfenbein, J. L. (1991). The effects of visual barriers used during auditory training on sound transmission. Journal of Speech and Hearing Research, 34(3), pp. 694-696.

Pichora-Fuller, M. K. and Singh, G. (2006). Effects of age on auditory and cognitive processing: Implications for hearing aid fitting and audiologic rehabilitation. Trends in Amplification, 10(1), pp. 29-59.

Plant, G. (1997). Auditory training. Seminars in Hearing, 18(2), pp. 117-127.

Rajan, R., Irvine, D. R., Wise, L. Z. and Heil, P. (1993). Effect of unilateral parital cochlear lesions in adults cats in the representation of lesioned and unlesioned cochleas in primary auditory cortex. Journal of Comparative Audiology, 338(1), pp. 17-49.

Recanzone, G.H., C.E.Schreiner, M.M.Merzenich. (1993). Plasticity in the frequency representation of primary auditory cortex following discrimination training in adult owl monkeys. Journal of Neuroscience, 13: 87-103.

Rubinstein, A. and Boothroyd, A. (1987). Effect of two approaches to auditory training on speech recognition by hearing-impaired adults. Journal of Speech and Hearing Research, 30, pp. 153-160.

Russo, N. M., Nicol, T. G., Zecker, S. G., Hayes, E. A. and Kraus, N. (2004). Auditory training improves neural timing in the human brainstem. Behavioural Brain Research, 156, pp. 95-103.

Shewell, C. (1998). The effect of perceptual training on the ability to use the vocal profile analysis scheme. International Journal of Language and Communication Disorders, 33 (Suppl), pp. 322-326.

Sivak, M., Hill, C. S. and Henson, D. L. (1984). Improved driving performance following perceptual training in persons with brain damage. Archives of Physical Medicine and Rehabilitation, 65(4), pp. 163-16.

Stacey, P. C. and Summerfield, A. Q. (2007). Effectiveness of computer-based auditory training in improving the perception of noise-vocoded speech. Journal of the Acoustical Society of America, 121(5), pp. 2923-2935.

Stecker, G. C., Bowman, G. A., Yund, E. W., Herron, T. J., Roup, C. M. and Woods, D. L. (2006). Perceptual training improves syllable identification in new and experienced hearing aid users. Journal of Rehabilitation Research \& Development, 43(4), pp. 537-552.

Sweetow, R. W. (2007). Auditory training. Seminars in Hearing, 28(2), pp. 87-88.

Sweetow, R. W. (2005). Training the adult brain to listen. Hearing Journal, 58(6), pp. 10-16.

Sweetow, R. W. and Henderson-Sabes, J. (2004). The case for LACE: Listening and auditory communication enhancement training. The Hearing Journal, 57(3), pp. 32-38.

Sweetow, R. and Palmer, C. (2005). Efficacy of individual auditory training in adults: a systematic review of the evidence. Journal of American Academy of Audiology, 16, pp. 494-504.

Syka, J. (2002). Plastic changes in the central auditory system after hearing loss, restoration of function and during learning. Physiological Reviews, 82(3), pp. 601-636.

Taylor, M. M., Schaeffer, J. N., Blumenthal, F. S. and Grisell, J. L. (1971). Perceptual training in patients with left hemiplegia. Archives of Physical Medicine \& Rehabilitation, 52(4), pp. 163-169.

Tremblay, K. L. (2007). Training-related changes in the brain: Evidence from human auditory-evoked potentials. Seminars in Hearing, 28(2), pp. 120-132.

Tremblay, K. L. and Kraus, N. (2002). Auditory training induces asymmetrical changes in cortical neural activity. Journal of Speech, Language, and Hearing Research, 45(3), pp. 564-572.

Tremblay, K. L., Kraus, N., Carrell, T. D. and McGee, T. (1997). Central auditory system plasticity: generalisation to novel stimuli following listening training. Journal of the Acoustical Society of America, 102(6), pp. 3762-3775. 
Trudeua, M., Overbury, O. and Conrod, B. (1990). Perceptual training and figure-ground performance in low vision. Journal of Visual Impairment and Blindness, 84 (5), pp. 204-206.

Tye-Murray, N. (2004). Foundations of Aural Rehabilitation. Children, Adults \& their Family Members $\left(2^{\text {nd }}\right.$ edition). New York: Thomson-Delmar Learning.

Von Wedel, H., Von Wedel, U. C. and Streppel M. (1990). Fine structure analysis of speech signals. Hearing aids and perceptual training. Acta Oto-Laryngologica Supplement, 469, pp. 236-244.

Wang, Y., Jongman, A. and Sereno, J. A. (2003). Acoustic and perceptual evaluation of Mandarin tone productions before and after perceptual training. Journal of Acoustical Society of America, 113(2), pp. 1033-1043.

Watts, W. J. (1977). The rehabilitation of adults with acquired hearing loss. British Journal of Audiology, 11(4), pp. 103-110.

Wood, D. L. and Yund, E. W. (2007). Perceptual training of phoneme identification for hearing loss. Seminars in Hearing, 28(2), pp. 110-119.

Wright, B. A. (2007). Hearing lesions: perceptual learning on basic auditory skills. The Hearing Journal, 60(2), pp. 10-14.

Zurek, P. M. (2004). Auditory training available now. Hearing Journal, 57(12), pp. 57.

Table 1. Search strategy 1 and 2 used to identify evidence for review

\begin{tabular}{|c|c|c|}
\hline Action & Terms \& Rationale & Hits \\
\hline $\begin{array}{l}\text { SEARCH } 1 \\
\text { Multifield search }\end{array}$ & Specification of the intervention and patient groups not interested in & \\
\hline $\begin{array}{l}\text { Search terms used } \\
\text { Limits } \\
\text { Remove duplicates }\end{array}$ & $\begin{array}{l}\text { auditory training (title) OR perceptual training (title) } \\
\text { OR listening training (title) } \\
\text { NOT cochlear implant\$ (title) NOT child\$ (all fields) NOT } \\
\text { infant\$ (all fields) } \\
\text { "English language" and "human" } \\
\text { Checks and removes duplicate records }\end{array}$ & $\begin{array}{l}59 \\
42\end{array}$ \\
\hline $\begin{array}{l}\text { SEARCH } 2 \\
\text { Advanced search }\end{array}$ & $\begin{array}{l}\text { Keyword search for relevant studies without "Auditory Training" in } \\
\text { title }\end{array}$ & \\
\hline $\begin{array}{l}\text { Search terms used } \\
\text { Limits } \\
\text { Remove duplicates }\end{array}$ & $\begin{array}{l}\text { auditory training (keyword) } \\
\text { AND } \\
\text { adult\$ (title) } \\
\text { "English language" and "human" }\end{array}$ & $\begin{array}{r}203 \\
170276 \\
19 \\
\mathbf{1 2}\end{array}$ \\
\hline & $\begin{array}{r}\text { TOTAL hits from Search } 1 \text { and } 2 \\
2 \mathrm{x} \text { duplicates removed }\end{array}$ & $\begin{array}{l}54 \\
52\end{array}$ \\
\hline
\end{tabular}


Table 2. Summary of exclusion criteria

\begin{tabular}{|l|r|}
\hline Reason for exclusion & Number excluded \\
\hline $\begin{array}{l}\text { Intervention used } \\
\text { (audio-visual format, simulated speech) }\end{array}$ & 5 \\
\hline $\begin{array}{l}\text { Patient group used } \\
\text { (children, cochlear implant users, normal hearing participants, profoundly deaf patients, } \\
\text { visually-impaired individuals, stroke/brain damaged patients, APD patients) }\end{array}$ & 15 \\
\hline $\begin{array}{l}\text { Outcome measure used } \\
\text { (rate of hearing aid return, language learning, sound transmission) }\end{array}$ & 1 \\
\hline Combination of unsuitable intervention, patient group \& outcome measure & 15 \\
\hline Descriptive (editorial comment rather than research) & 9 \\
\hline Extension (of another study - not new evidence) & 1 \\
\hline \multicolumn{1}{|c|}{ Total excluded } & 46 \\
\hline
\end{tabular}

Table 3. Overview of studies included in this review

\begin{tabular}{|c|c|c|c|c|c|}
\hline Study & Methodology & Intervention & $\begin{array}{l}\text { Outcome } \\
\text { Measures }\end{array}$ & Results & Criticisms \\
\hline $\begin{array}{c}\text { 1. Bode \& } \\
\text { Oyer (1970) } \\
\qquad \odot\end{array}$ & $\begin{array}{l}\text { Non-randomised } \\
\text { observational case } \\
\text { control } \\
\mathrm{N}=32 \text { adults with } \\
\text { mild SNHL } \\
\text { assigned to } 4 \\
\text { matched groups }\end{array}$ & $\begin{array}{l}5 \times 25 \text { min training } \\
\text { sessions over } 1 \text { day } \\
\text { - two listening } \\
\text { conditions \& two } \\
\text { response formats (open } \\
\text { v's closed set) }\end{array}$ & $\begin{array}{l}\text { Speech } \\
\text { discrimination pre \& } \\
\text { post training } \\
3 \text { tests used: } \\
\text { CID W-22 } \\
\text { Rhyme test } \\
\text { Semi-diagnostic test }\end{array}$ & $\begin{array}{l}\text { Improved speech } \\
\text { discrimination from } \\
\text { training found with } \\
\text { the W-22 and } \\
\text { Rhyme tests }\end{array}$ & $\begin{array}{l}\text { No control group, } \\
\text { not randomised, not } \\
\text { blinded, no } \\
\text { follow-up for } \\
\text { long-term effects, } \\
\text { training all on } 1 \text { day }\end{array}$ \\
\hline $\begin{array}{l}\text { 2. Burk \& } \\
\text { Humes } \\
(2008) \\
\text { ○) }\end{array}$ & $\begin{array}{l}\text { Non-randomised } \\
\text { observational case } \\
\text { control } \\
\mathrm{N}=8 \text { adults with } \\
\text { mild-moderate } \\
\text { SNHL }\end{array}$ & $\begin{array}{l}\text { Word \& sentence } \\
\text { stimuli (lexically hard } \\
\text { and easy) presented in } \\
\text { noise via computer } \\
\text { through insert } \\
\text { headphones over 20-24 } \\
\text { sessions }\end{array}$ & $\begin{array}{l}\text { Open \& closed-set } \\
\text { word recognition } \\
\text { performance in noise }\end{array}$ & $\begin{array}{l}\text { Improvement with } \\
\text { trained words- } \\
\text { generalised to } \\
\text { unfamiliar talker. } \\
\text { Retained for } 14 \\
\text { weeks }\end{array}$ & $\begin{array}{l}\text { No control group, } \\
\text { not randomised, not } \\
\text { blinded, small study } \\
\text { group, participants } \\
\text { paid and offered } \\
\text { bonus incentives - } \\
\text { bias? }\end{array}$ \\
\hline $\begin{array}{l}\text { 3. Kricos \& } \\
\text { Holmes } \\
(1996) \\
\qquad \odot\end{array}$ & $\begin{array}{l}R C T \text { ( } 3 \text { groups: } \\
\text { control, analytic } \\
\text { training \& active } \\
\text { listening) } \\
\mathrm{N}=78 \text { adults with }\end{array}$ & $\begin{array}{l}2 \text { approaches - analytic } \\
\text { AT (syllable drills) } \\
\text { versus active listening } \\
\text { training (linguistic \& } \\
\text { situational cues) } \\
2 \times 1 \text { hour sessions over }\end{array}$ & $\begin{array}{l}\text { Measures of: speech } \\
\text { recognition, hearing } \\
\text { handicap perception } \\
\& \text { psychosocial } \\
\text { function }\end{array}$ & $\begin{array}{l}\text { Active listening } \\
\text { group showed } \\
\text { significant } \\
\text { improvement. No } \\
\text { effect found for } \\
\text { analytic AT group }\end{array}$ & $\begin{array}{l}\text { Randomisation } \\
\text { process not blinded, } \\
\text { no measure of } \\
\text { long-term benefit }\end{array}$ \\
\hline
\end{tabular}




\begin{tabular}{|c|c|c|c|c|c|}
\hline & SNHL & 4 weeks & & & \\
\hline $\begin{array}{l}\text { 4.Rubinstein } \\
\text { \& Boothroyd } \\
(1987) \\
\odot\end{array}$ & $\begin{array}{l}\text { Non-randomised } \\
\text { observational case } \\
\text { control } \\
\mathrm{N}=20 \text { adults with } \\
\text { mild-moderate } \\
\text { SNHL assigned to } 2 \\
\text { matched groups }\end{array}$ & $\begin{array}{l}2 \text { training approaches: } \\
\text { synthetic approach } \\
\text { (consonant recognition) } \\
\& \text { synthetic+ analytic } \\
\text { approach (consonant } \\
\text { recognition + sentence } \\
\text { perception) } \\
\text { ( } 8 \text { x } 1 \text { hour training } \\
\text { sessions over } 4 \text { weeks) }\end{array}$ & $\begin{array}{l}3 \text { tests of speech } \\
\text { recognition: } \\
\text { - CUNY NST } \\
\text { - low predictability } \\
\text { items of RSPIN } \\
\text { - high predictability } \\
\text { items of RSPIN }\end{array}$ & $\begin{array}{l}\text { Small significant } \\
\text { improvement in } \\
\text { speech recognition } \\
\text { in both training } \\
\text { paradigms (retained } \\
\text { after } 1 \text { month) }\end{array}$ & $\begin{array}{l}\text { Small study, } \\
\text { subjects acted as } \\
\text { own control - no } \\
\text { 'no-treatment' } \\
\text { control group, not } \\
\text { randomised }\end{array}$ \\
\hline $\begin{array}{l}\text { 5. Stecker et } \\
\text { al (2006) } \\
\odot\end{array}$ & $\begin{array}{l}R C T \text { (Initial \& } \\
\text { delayed training } \\
\text { group) } \\
\text { Experiment 1: } \\
\text { New HA users } \\
(\mathrm{N}=23) \\
\text { Experiment 2: } \\
\text { Experienced HA } \\
\text { users }(\mathrm{N}=8)\end{array}$ & $\begin{array}{l}\text { Perceptual training of } \\
\text { syllables (PC based) } \\
-1 \text { hour/day for } 5 \\
\text { days each week for total } \\
8 \text { weeks }\end{array}$ & $\begin{array}{l}\text { Syllable } \\
\text { identification } \\
\text { performance in noise } \\
\text { on nonsense syllable } \\
\text { test (NST) }\end{array}$ & $\begin{array}{l}\text { Significant } \\
\text { improvement in } \\
\text { syllable } \\
\text { identification in } \\
\text { both experimental } \\
\text { groups (retained } \\
\text { after } 8 \text { weeks) }\end{array}$ & $\begin{array}{l}\text { Small study, only } \\
\text { male participants, } \\
\text { participants paid - } \\
\text { potential bias, } \\
\text { randomisation } \\
\text { process not blinded }\end{array}$ \\
\hline $\begin{array}{l}\text { 6. Sweetow } \\
\text { \& Palmer } \\
(2005) \\
\odot\end{array}$ & $\begin{array}{l}\text { Systematic Review } \\
\text { (6 studies reviewed) }\end{array}$ & $\begin{array}{l}\text { Clinical question aimed } \\
\text { to assess the efficacy of } \\
\text { individual AT on } \\
\text { communication skills of } \\
\text { adults with hearing } \\
\text { impairment }\end{array}$ & $\begin{array}{l}\text { Communication } \\
\text { skills }\end{array}$ & $\begin{array}{l}\text { Some evidence of } \\
\text { efficacy - but } \\
\text { evidence-base not } \\
\text { robust enough }\end{array}$ & $\begin{array}{l}\text { Limited appraisal of } \\
\text { statistical analyses } \\
\text { used, included } \\
\text { studies that used } \\
\text { audio-visual } \\
\text { material }\end{array}$ \\
\hline
\end{tabular}

Key to abbreviations: $\mathrm{SNHL}=$ sensorineural hearing loss; CID W-22 $=$ Central Institute for the Deaf Word List 22; AT = auditory training; CUNY NDT = City University of New York Nonsense Syllable Test; RSPIN = Revised Speech Perception in Noise; HA = Hearing Aid; RCT = Randomised Controlled Trial; $\odot=$ support for AT 


\section{Studies identified from search -} potentially relevant to clinical question: identified studies with

Intervention: auditory training OR perceptual training OR listening training Patient group: adults

$$
\mathbf{n}=\mathbf{5 2}
$$

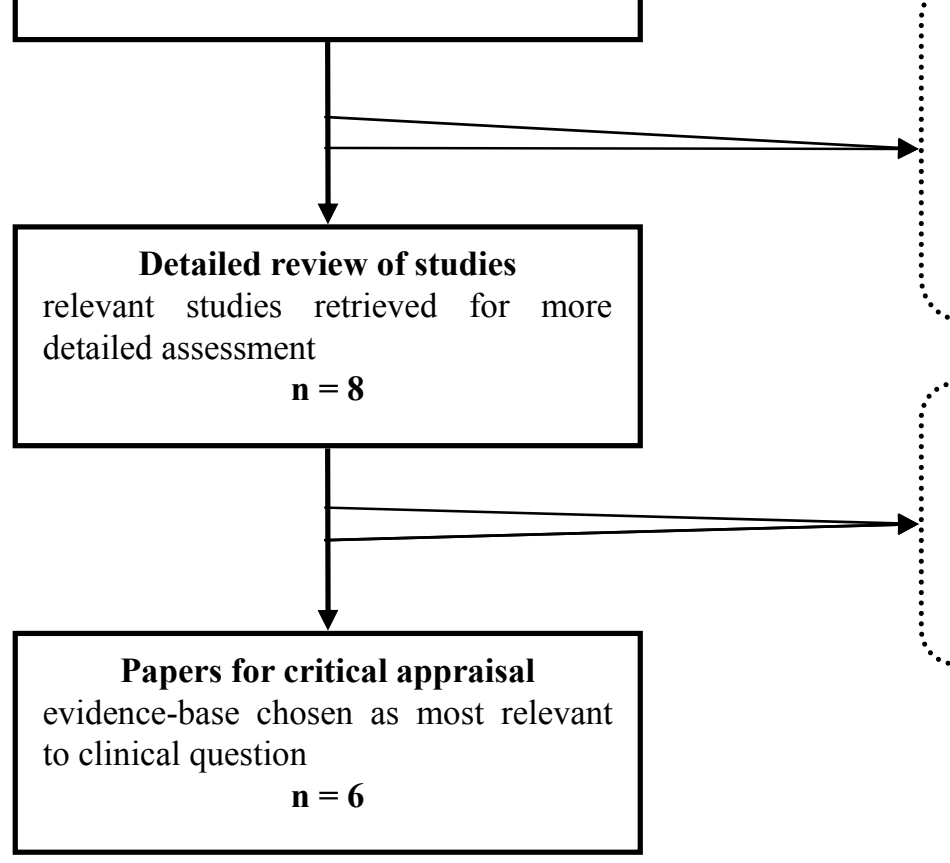

Exclusion of studies:

reasons for exclusion included:

intervention, participants or outcome measures not suitable for answering clinical question

$$
n=45
$$

\section{Exclusion of study:}

reason: extension of another study already included \& inappropriate outcome measure

$$
\mathbf{n}=\mathbf{2}
$$

Figure 1. Process of selecting evidence for review $(\mathrm{n}=$ number of studies $)$ 